\title{
To Study The Association Between Iron Deficiency And Simple Febrile Seizures
}

\author{
Vijayalakshmi Ambati ${ }^{1}$, Sudhakar Ajmera ${ }^{2}$, Siddhartha $\mathrm{G}^{3}$ \\ 1 (Associate Professor, Department Of Pediatrics, MGM Hospital, Kakatiya Medical College, Warangal, \\ Telangana) \\ 2(Assistant Professor, Department Of Pediatrics, MGM Hospital, Kakatiya Medical College, Warangal, \\ Telangana) \\ 3(Post Graduate, Department Of Pediatrics, MGM Hospital, Kakatiya Medical College, Warangal, Telangana)
}

\begin{abstract}
:
Design: Case control study,

Setting: Pediatric department of a tertiary care teaching hospital,

Participants: Cases were children of age group 6 months to 5 years presenting with simple febrile seizures. Controls were children of same age group presenting with short febrile illness without any seizures,

Materials and Methods: In this study, cases 101 children with febrile seizures and 101 febrile children without seizures were taken. (Control. All children were aged between 6 months to 5 years. The groups were matched in age and gender. Blood samples were collected from each child for measuring of blood indices such as $H B, M C V$ and MCH. Serum Ferritine, serum iron, total iron binding capacity (TIBC), \% saturation of transferine are measured and compared,

Results: The peak incidence of febrile seizures is between 6months and 1 year of age. The mean age being 18 months with male: female ratio of 1.5: 1. Significantly, a greater proportion of children with febrile seizures have low Serum Ferrine $(<50 \mathrm{ng} / \mathrm{ml})$; low HB $(<=10 \mathrm{gm} / \mathrm{dl})$, low MCV $(<=75 \mathrm{fl})$ and $\mathrm{MCH}(28)$ and low transferrine saturation $(<=15)$ as compared to controls. Although there were low levels of serum iron and increased total iron binding Capacity these variables did not achieve statistical significance. The odds of children to have febrile seizures is 2.7 when compared to controls who are not anemic, Conclusions: In our study Plasma Ferritin level and blood indices are significantly lower in children with febrile seizures suggesting that iron deficient children are more prone to febrile seizures.
\end{abstract}

Keywords: children, febrile seizures, iron deficiency.

\section{Introduction}

Febrile seizures are the most common cause of seizures in children, occurring in 2-5\% of children [1]. Febrile seizures are defined as seizures resulting from fever. It occurs in children of 6 months to 6 (full six) years of age. Independent risk factors for febrile seizures were height of temperature, history of seizures or febrile seizures in the family, head injuries, maternal smoking alcohol consumption during pregnancy and perinatal exposure to antiretrovirals $[2,3,4,5,6]$. Since a risk of FS is the probability of its subsequent development into seizures and epilepsy, various studies have been carried out with the purpose of identifying correctable risk factors to reduce the prevalence of FS and, hence, of epilepsy and seizures.[2,3,7,8,9]. Iron deficiency is the most common micronutrient deficiency worldwide and is a preventable and treatable condition [10]. Iron is essential for the brain energy metabolism, for metabolism of neurotransmitters and for myelination. Thus iron deficiency may alter the seizures threshold of a child [11]. Iron deficiency is postulated as risk factor for FS in children and it is an easily correctable condition [7, 12, and 13]. We therefore decided to study the relationship between iron deficiency anemia and FS in children hospitalized in MGM Hospital, Warangal City.

\section{Methodology}

This case study was done in the Department of pediatrics MGM Hospital, during January, 2014 and January 2015. Ethical clearance was obtained for the study from the Ethical committee, Medical College, Warangal. Cases were children of age group 6 months to 5 years presenting with simple febrile seizures to the pediatric emergency department and wards of the hospital during the study period. Diagnostic criteria for simple febrile seizures (based on AAP clinical practice guide lines) cases included, seizures associated with fever and the seizures were generalized, short duration (less than 15 minutes), no recurrence of seizures within 24 hours, otherwise child is healthy and without any neurological abnormality before and after the episode of seizures with the age group between the 6 months to 5 years [4]. Consecutive cases were selected for the study and concurrent controls were selected from the same setting and included febrile children of age group 6 months to 5 years who presented with short duration of fever but without seizures, matched by age and sex. Children 
presenting with atypical febrile seizures, those having any signs of central nervous system infection, those with any chronic neurological problems, neurological deficit, hematological problems like hemolytic anemia, bleeding, coagulation disorders, hematological malignancy and those who were on iron supplementation and children with chronic illness were excluded from the study. Ratio of cases: controls 1:1. Sample size: From pilot study, the SD (standard deviation) of ferritin was found to be 20 . In order to detect a difference of 10 with $5 \%$ level of significance and $80 \%$ power, the sample size needed was 101 in each group.

After getting informed consent from the parents of cases and controls detailed history was elicited and clinical examination and findings are entered in the proforma. Blood samples were collected after control of seizures and measures of serum ferritine (it is done by Chemiluminescence immune assay), serum iron estimation (it is done by colorimetric method), Total iron binding capacity estimation (it is done by ferrozine method), Transferrine saturation estimation (it is done by colorimetric method) and measures of HB, MCV and $\mathrm{MCH}$ are done by using auto-analyzer (Coulter Counter).

\section{Statistical Analysis}

The effect of iron status on febrile seizures with odds ratio (OR) and 95\% confidence limit was arrived by univariant analysis. The value of OR was considered significant if the probability (P) was $<0.05$. All continuous data was analyzed by the use of t-test or Mann Whitney U test. All proportionate data was analyzed with chi-square or Fischer exact test. Iron deficiency anemia was defined as the Hb concentration falling 2 standard deviation (SD) below the mean for age and sex. Serum iron concentration $<50 \mathrm{mg} / \mathrm{dl}, \mathrm{PF}<50 \mathrm{mg} / \mathrm{l}$, transferring sat $<15$ and $\mathrm{TIBC}>450 \mathrm{mcg} / \mathrm{dl}$ in children confirm this status.

\section{Results}

Table: Incidence of febrile seizures with respect to age and gender.

\begin{tabular}{|c|c|c|c|c|c|c|}
\hline \multirow{2}{*}{ AGE } & \multicolumn{2}{|c|}{ MALES } & \multicolumn{2}{c|}{ FEMALES } & \multicolumn{2}{c|}{ TOTAL } \\
\cline { 2 - 7 } & $\mathrm{N}$ & $\%$ & $\mathrm{~N}$ & $\%$ & $\mathrm{~N}$ & $\%$ \\
\hline $6 \mathrm{M}-1 \mathrm{Y}$ & 19 & 18.8 & 15 & 14.8 & 34 & 33.8 \\
\hline $1-2$ & 18 & 17.8 & 7 & 6.8 & 25 & 24.8 \\
\hline $2-3$ & 12 & 11.8 & 12 & 11.8 & 24 & 23.8 \\
\hline $3-5$ & 11 & 10.8 & 7 & 6.8 & 18 & 17.8 \\
\hline
\end{tabular}

A maximum incidence of febrile seizures is found in the age group of 6 months - 1 year (34\%), followed by 1 year -2 year $(25 \%)$ and 2 year -3 year $(23.5 \%)$. The mean age being 18 months. The incidence of febrile seizures is found to be higher in males (60\%) with a male : female ratio of 1.5 Table: Mean value of serum ferritin and blood indices among cases and controls

\begin{tabular}{|c|c|c|c|c|c|}
\hline \multirow{2}{*}{ VARIABLES } & \multicolumn{2}{|c|}{ CASES } & \multicolumn{2}{c|}{ CONTROLS } & \multirow{2}{*}{ P VALUE } \\
\cline { 2 - 5 } & MEAN & SD & MEAN & SD & \\
\hline SE.FERITIN(ng/ml) & 34.92 & 32 & 72 & 39 & $<0.00$ \\
\hline SE.IRON(mcg/dl) & 66.86 & 36.4 & 67 & 54 & 0.96 \\
\hline TIBC(mcg/dl) & 406 & 85 & 406 & 95 & 1 \\
\hline$\%$ SAT OF TRANSFERIN & 14.8 & 9.85 & 23.4 & 13.6 & $<0.00$ \\
\hline HB\% & 10.2 & 1.5 & 11 & 1.76 & $<0.00$ \\
\hline
\end{tabular}

The mean ferritin level among febrile seizures group is found to be $34.9+/-32 \mathrm{ng} / \mathrm{ml}$ whereas in controls it is $72+/-39 \mathrm{ng} / \mathrm{ml},(\mathrm{P}=0.00)$. The mean Hemoglobin (HB) for cases is $10.2+/-1.5 \mathrm{gm} / \mathrm{dl}$, whereas in controls it is $11+/-1.7 \mathrm{gm} / \mathrm{dl}(\mathrm{P}=0.00)$. The mean Corpuscular Volume (MCV) for cases is $76+/-8.5 \mathrm{fl}$ and for controls it is 79.5+/-7.5fl, $(\mathrm{P}=0.02)$. The mean Corpuscular Hemoglobin $(\mathrm{MCH})$ for cases is $27.7+/-3.1 \mathrm{pg}$ and for controls it is 28.7+/-3.6pg $(\mathrm{P}=0.11)$. Thus the mean levels of blood indices are found to be significantly on the lower side among children with febrile seizures when compared to the children who did not have febrile seizures, which is statistically significant.

Table: Proportions of Se.ferritin and blood indices among cases and controls

\begin{tabular}{|c|c|c|c|c|c|c|}
\hline \multirow{2}{*}{ VARIABLES } & \multirow{2}{*}{ CUTOFF VALUES } & \multicolumn{2}{|c|}{ CASES } & \multicolumn{2}{|c|}{ CONTROLS } & \multirow{2}{*}{$\begin{array}{c}\mathrm{P} \\
\text { VALUE }\end{array}$} \\
\hline & & $\mathrm{N}$ & $\%$ & $\mathrm{~N}$ & $\%$ & \\
\hline \multirow{2}{*}{ SE.FERITIN(ng/ml) } & $<50$ & 67 & 66.3 & 53 & 52.4 & \multirow{2}{*}{0.04} \\
\hline & $>50$ & 34 & 33.6 & 48 & 47.5 & \\
\hline \multirow{2}{*}{ SE.IRON(mcg/dl) } & $<=50$ & 56 & 55.4 & 53 & 52.4 & \multirow{2}{*}{0.67} \\
\hline & $>50$ & 45 & 44.5 & 48 & 47.5 & \\
\hline \multirow{2}{*}{ TIBC(mcg/dl) } & $>=450$ & 59 & 58.4 & 53 & 52.4 & \multirow{2}{*}{0.28} \\
\hline & $<450$ & 42 & 41.5 & 48 & 47.5 & \\
\hline \multirow{2}{*}{$\mathrm{HB} \%$} & $<=10$ & 64 & 63.3 & 37 & 36.6 & \multirow{2}{*}{0} \\
\hline & $>10$ & 37 & 36.6 & 64 & 63.3 & \\
\hline MCV (fl) & $<=75$ & 70 & 69.3 & 38 & 37.6 & 0 \\
\hline
\end{tabular}




\begin{tabular}{|c|c|c|c|c|c|c|} 
& $>75$ & 31 & 30.6 & 63 & 62.3 & \\
\hline \multirow{2}{*}{$\mathrm{MCH}(\mathrm{pg})$} & $<28$ & 64 & 63.3 & 48 & 47.5 & \multirow{2}{*}{0} \\
\cline { 2 - 6 } & $>28$ & 37 & 36.6 & 53 & 52.4 & \\
\hline \multirow{2}{*}{$\mathrm{MCHC}(\mathrm{mg} / \mathrm{dl})$} & $<30$ & 58 & 57.4 & 42 & 41.5 & \multirow{2}{*}{0.25} \\
\cline { 2 - 6 } & $>30$ & 43 & 42.5 & 59 & 58.4 & \\
\hline TRSAT OF & $<=15$ & 65 & 64.3 & 43 & 42.5 & \multirow{2}{*}{0} \\
\cline { 2 - 6 } & $>15$ & 36 & 35.6 & 58 & 57.4 & \\
\hline
\end{tabular}

Sixty seven children $(66.9 \%)$ with febrile seizures have serum ferritine level $<50 \mathrm{ng} / \mathrm{ml}$ whereas 53 children

Fifty six children (56) with febrile seizures have serum iron levels $<=50$, when compared to 53 (53\%) children in control group $(\mathrm{P}=0.67)$. Fifty nine children $(59 \%)$ with febrile seizures have TIBC levels $>=450$ whereas 53 children $(53 \%)$ in control group have TIBC level $>=450(\mathrm{P}=0.28)$. Sixty five children $(65 \%)$ with febrile seizures have transferrin saturation $<=15$ whereas 43 children in control group have transferrin saturation $<=15$ $(\mathrm{P}=0.00)$. The number of children with hemoglobin $<=10 \mathrm{gm} / \mathrm{dl}$ is $64(64 \%)$ in febrile seizures group whereas among controls it is $46(45.1 \%)(\mathrm{P}=0.01)$. The Mean Capsular Volume $<=75 \mathrm{fl}$ is seen in 70 (69.9) cases, whereas in controls it is $38(37.6 \%)(\mathrm{P}=0.00) .64$ children $(64 \%)$ in cases and 43 children (43\%) in controls have Mean Corpuscular Hemoglobin $<28 \mathrm{pg}(\mathrm{P}=0.00)$. Thus a significant proportion of children with febrile seizures have low serum ferritin, Hemoglobin and Mean Capsular Volume and Mean Corpuscular Hemoglobin than did the controls. However the proportion of children with low serum iron, TIBC, Mean Corpuscular Hemoglobin concentration among those with febrile seizures and controls did not achieve statistical significance.

Table: Odds ratio and relative risk of cases when compared to controls for Blood indices.

\begin{tabular}{|c|c|c|c|c|c|}
\hline \multirow{2}{*}{ VARIABLES } & $\begin{array}{c}\text { CUTOFF } \\
\text { VALUE }\end{array}$ & $\begin{array}{c}\text { ODDS } \\
\text { RATIO }\end{array}$ & $\begin{array}{c}\text { RELATIVE } \\
\text { RISK }\end{array}$ & $\begin{array}{c}\text { CONFIDENCE } \\
\text { INTERVAL }\end{array}$ & P VALUE \\
\hline \multirow{2}{*}{ SE.FERITIN(nag/ml) } & $<50$ & 2.7 & 1.78 & $1.1-3.6$ & 0.04 \\
\cline { 2 - 6 } & $>50$ & 1 & - & Reference & \\
\hline \multirow{2}{*}{ SE.IRON(mcg/dl) } & $<=50$ & 1.2 & 1.05 & $0.64-1.9$ & 0.67 \\
\cline { 2 - 7 } & $>50$ & 1 & - & Reference & \\
\hline \multirow{2}{*}{ TIBC(mcg/dl) } & $>=450$ & 1.5 & 1.11 & $0.77-2.34$ & 0.28 \\
\cline { 2 - 7 } & $<450$ & 1 & - & Reference & \\
\hline \multirow{2}{*}{$\%$ TRAT OF } & $<=15$ & 2.45 & 1.5 & $1.12-3.5$ & 0 \\
\cline { 2 - 7 } & $>15$ & 1 & - & Reference & \\
\hline \multirow{2}{*}{ HB\% $\%$} & $<=10$ & 2.6 & 1.4 & $1.7-3.6$ & $0.00<$ \\
\cline { 2 - 7 } & $>10$ & 1 & - & Reference & \\
\hline
\end{tabular}

Odds of children with febrile seizures having low serum ferritin level is 2.7 when compared to those who did not have febrile seizures. OR (95\% of C.I) $=2.7(1.1-3.6)$

Odds of children with febrile seizures having low serum iron are 1.2 when compared to those who did not have febrile seizures. OR (95\% of C.I) $=1.2(0.64-1.9)$

Odds of children with febrile seizures having high total iron binding capacity are 1.5 when compared to those who did not have febrile seizures. OR $(95 \%$ of C.I $)=1.5(0.7-2.3)$

Odds of children with febrile seizures having decreased transferring saturation are 2.4 when compared to those who did not have febrile seizures. OR $(95 \%$ of C.I $)=2.4(1.12-3.5)$

Odds of children with febrile seizures having low hemoglobin are 2.6 when compared to those who did not have febrile seizures. OR $(95 \%$ of C.I $)=2.6(1.7-3.6)$

Odds of children with febrile seizures having low Mean Corpuscular Volume are 3.7 when compared to those who did not have febrile seizures. OR $(95 \%$ of C.I $)=3.7(2.0-6.7)$

Odds of children with febrile seizures having low Mean Corpuscular Hemoglobin is 2.33 when compared to those who did not have febrile seizures which is statistically significant OR ( $95 \%$ of C.I $)=2.33$

\section{Discussion}

In our study to detect iron status as a possible risk factor for febrile seizures 101 cases and 101 age and sex matched controls are studied and analyzed.

In the present study we found the peak indices of febrile seizures occur during $6 \mathrm{M}$ to 1 year of age and the mean age is 18 months. This is comparable to previous studies. The peak age of onset being 14-18 months of age as per Nelson text book of pediatrics [1]. Berg et al. in his study found that the peak incidence is between 18 and 24 months [9]. Similarly Naveedur Rehman et al. reported the peak incidence at 22 Months [19].

The present study depicts that the incidence of febrile seizures is slightly higher in boys than in girls and the male: female ratio 1.5:1. This is similar to the study by Berg et al [9]. While Naveedur Rehman et al. reported no gender difference in their study[19]. 
The mean serum ferritin level in our study is $34.92 \mathrm{ng} / \mathrm{ml}$. whereas Daoud as et al. in his study group from Jordan found that the mean ferritin level was $29.5 \mathrm{ng} / \mathrm{ml}[7]$.

Daoud As et al. in his study found that a significant proportion of children with febrile seizures had only low serum ferritin level [7].

The proportion of children with febrile seizures having low hemoglobin, Mean Corpuscular Volume and Mean Corpuscular Hemoglobin were not statistically significant. Whereas our study demonstrates a statistically significant difference in the proportion of children with febrile seizures have not only low serum ferritin but also low hemoglobin and low transferring saturation. This is similar to the findings reported by Naveedur Rehman et al. in his study at Karachi [19].

The children in Western countries if they are iron deficient are mostly in the early stage. So the study done by Daoud As et al. in Jordan has a significant proportion of children with low ferritin level, without significant difference in $\mathrm{HB}, \mathrm{MCV}$ and $\mathrm{MCH}$. Whereas Indian children / children of our neighboring country Pakistan are in the stages of latent or overt iron deficiency. So our study and the study done in Karachi by Naveedur Rehman et al. had a significantly greater proportion of children with not only low serum ferritin but also low $\mathrm{HB} \%, \mathrm{MCV}$, transferring saturation and $\mathrm{MCH}$.

As similar to previous studies by Daoud As et al., Naveedur Rehman et al. and Alfredo Pisacane et al [7], [19], [13] Our study also demonstrates an association between iron deficiency and febrile seizures. Thus iron deficiency is one of the possible risk factor for febrile seizures. Developmental problems, risk of pediatric stroke, the occurrence of febrile seizures and breath holding spells are perhaps the tip of the iceberg, of the neurological consequences of iron deficiency. With appropriate recognition, treatment is better yet, prevention the neurological squeal of iron deficiency is entirely preventable and perhaps reversible.

\section{References}

[1]. Johnston MV. Seizures in childhood. In: Kleigman RM, Behrman RE, Jenson HB, Stanton BP. Nelson Text book of Pediatrics, $18^{\text {th }}$ Edition Philadelphia: Saunders Elsevier; 2007. P.2457-8.

[2]. Nelson KB, Ellenberg JH. Prenatal and perinatal antecedents of febrile seizures. Ann Neurol. 1990; 27:127-31. [Pub Med]

[3]. Greenwood R, Golding J, Ross E, Verity C. Prenatal and perinatal antecedents of febrile convolutions and afebrile seizures: Data from a national cohort study. Pediatric Perinat Epidemiol. 1998; 12:76-95. [PubMed]

[4]. American Academy of Pediatrics Steering Committee on Quality Improvement and Management. Classifying recommendations for clinical practice guidelines. Pediatrics. 2004;114:874-7. [PubMed]

[5]. Sadleir LG, Scheffer IE. Febrile seizuress. BMJ. 2007;334:307-11. [PMC free article][PubMed]

[6]. Steering Committee on Quality Improvement and Management, Subcommittee on Febrile Seizures American Academy of Pediatrics. Febrile seizures: Clinical practice guideline for the long term management of the child with simple febrile seizures. Pediatrics. 2008:121:1281-6. [PubMed]

[7]. Daoud AS, Batieha A, Abu-Ekteish F, Gharaibeh N, Ajlouni S, Hijazi S. Iron status: A possible risk factor for the first febrile seizures. Epilepsia. 2002;43:740-3. [PubMed]

[8]. Hartfield DS, Tan J, Yager JY, Rosychuk RJ, Spady D, Haines C, et al. The association between iron deficiency and febrile seizures in childhood. Clin Pediatr (Phila) 2009;48:420-6. [PubMed]

[9]. Berg AT, Shinnar S, Shapiro ED, Salomon ME, Crain EF, Hauser WA. Risk factors for first febrile seizures: A matched case control study. Epilepsies. 1995;36:334-41. [PubMed]

[10]. World Health Organisation. A guide for Program Managers. Geneva: WHO/NHD/013; 2001. Iron deficiency anemia. Assessment, prevention and control.

[11]. Beard J. Iron deficiency alters brain development and functioning. Nutr. 2003;133:1468-72S. [PubMed]

[12]. Kumari PL, Nair MK, Nair SM, Kailas L, Geetha S. Iron deficiency as a risk factor for simple febrile seizures: A case control study. Indian Pediatr. 2012;49:17-9. [PubMed]

[13]. Pisacane A, Sansone R, Impagliazzo N, Coppola A, et al. Iron deficiency anaemia and febrile convolutions: Case-control study in children under 2 years. BMJ.1996;313:343. [PMC free article][PubMed]

[14]. Kobrinsky NL, Yager JY, Cheang MS, Yatscoff RW, Tenenbein M. Does iron deficiency raise the seizuress threshold? J Child Neurol. 1995:10:105-9. [PubMed]

[15]. Talebian NM, Mosavi GA, Khojasteh MR. Relationship between febrile seizures and anemia. Iran J Pediatr. 2006;16:79-82.

[16]. Derakshanfar H, Abaskhanian A, Alimohammadi H, ModanlooKordi M. Association between iron deficiency anemia and febrile seizures in children. Med Glas (Zenica) 2012;9:239-42. [PubMed]

[17]. Madhavi MR, Makhlough A, Kosaryan M, Roshan P. Credibility of the measurement of serum ferritin and transferring receptor as indicators of iron deficiency anemia in hemodialysis patients. Eur Rev Med Pharmacol Sci. 2011;15:1158-62. [PubMed]

[18]. Momen AA, Nikfar R, Karimi B. Evaluation of iron status in 9 months to 5 year old children with febrile seizures: A case control study in the south west of Iran. Iran J Child Neurol. 2010;4:45-50.

[19]. Naveed-ur-Rehman, Billoo AG. Association between iron deficiency anemia and febrile seizuress. J Coll Physicians Surg Pak.2005;15:338-40. [PubMed] 